\title{
Aspectos da política de formação continuada de professores implementada pelos CEFAPROs de Mato Grosso
}

\author{
Ângela Rita Christofolo de Mello \\ Albina Pereira de Pinho Silva \\ Cleuza Regina Balan Taborda \\ Universidade do Estado de Mato Grosso (Brasil)
}

\section{Resumo}

artigo publiciza resultados de uma pesquisa realizada com o objetivo de analisar aspectos da política de formação continuada de professores institucionalizada nos Centros de Formação e Atualização dos Profissionais da Educação Básica (CEFAPROs) de Mato Grosso, no que tange à sua importância, como também ao atendimento às demandas e necessidades formativas dos docentes. A formulação do corpus analítico integrou dados qualitativos gerados por meio de questionários, com perguntas objetivas e subjetivas, respondidos em dezembro de 2017 pelos professores - colaboradores da pesquisa. Os resultados retrataram um contexto adverso e conflituoso em que mais de 50\% dos professores não reconhecem a importância dos CEFAPROs enquanto instâncias de formação continuada, uma vez que não atendem às demandas e às necessidades formativas docentes. Contudo, a conjuntura analisada, dentre outros aspectos, reedita que a oferta de formação continuada, necessariamente, pauta-se nas reflexões das ações realizadas pelos professores no interior das salas de aulas. Apreende-se, portanto, a necessidade da assunção da autonomia e protagonismo dos professores no processo de elaboração das propostas e planejamentos das ações de formação em atenção às suas próprias necessidades formativas.

Palavras-chave: Mato Grosso. Educação Básica. Formação continuada. CEFAPROs.

\section{Aspects of continuing teacher education policy implemented by CEFAPROs of Mato Grosso}

\section{Abstract}

The article make public results of a research carried out with the purpose of analyzing aspects of the institutionalized continuing education policy of teachers in the Centers of Formation and Updating of the Professionals of the Basic Education (CEFAPROs) of Mato Grosso, regarding its importance, as well as, attending the demands and formation needs of teachers. The formulation of the analytical corpus integrated qualitative data generated through questionnaires, with objective and subjective questions, answered in December 2017 by the teachers - collaborators of the research. The results portrayed an adverse and conflicting context in which more 
than $50 \%$ of teachers do not recognize the importance of CEFAPROs as continuing education instances, since they do not meet the demands and educational needs of teachers. However, the analyzed conjuncture, among other aspects, reiterates that the offer of continuing education, necessarily, is based on the reflections of the actions performed by teachers inside the classrooms. We apprehend, therefore, the need to assume the autonomy and protagonism of the teachers in the process of elaborating the proposals and planning of the formation actions in attention to their own formative needs.

Keywords: Mato Grosso. Basic education. Continuing education. CEFAPRO.

\section{Aspectos de la política de formación continua del profesorado implementada por los CEFAPROs de Mato Grosso}

\section{Resumen}

El artículo da a conocer los resultados de una investigación realizada con el objetivo de analizar aspectos de la política de educación continua institucionalizada de los docentes en los Centros de Formación y Actualización de los Profesionales de la Educación Básica (CEFAPRO) de Mato Grosso, en relación con su importancia, así como, atender las demandas y necesidades de formación de los docentes. La formulación del corpus analítico integró datos cualitativos generados a través de cuestionarios, con preguntas objetivas y subjetivas, respondidas en diciembre de 2017 por los docentes - colaboradores de la investigación. Los resultados retrataron un contexto adverso y conflictivo en el que más del $50 \%$ de los docentes no reconocen la importancia de los CEFAPROs como instancias de educación continua, ya que no satisfacen las demandas y necesidades educativas de los docentes. Sin embargo, la coyuntura analizada, entre otros aspectos, reitera que la oferta de educación continua, necesariamente, se basa en las reflexiones de las acciones realizadas por los docentes dentro de las aulas. Por lo tanto, se aprehende la necesidad de asumir la autonomía y el protagonismo de los docentes en el proceso de elaboración de las propuestas y la planificación de las acciones de formación en atención a sus propias necesidades formativas.

Palabras clave: Mato Grosso. Educación básica. Formación continua. CEFAPROs.

\section{Introdução}

Este texto compartilha os resultados de uma pesquisa financiada pela Fundação de Amparo à Pesquisa do Estado de Mato Grosso (FAPEMAT), Edital Induzido, Educação Estadual nº 011 /2016-2, com o objetivo de analisar a atuação dos CEFAPROs e as propostas de formação continuada ofertadas aos docentes da educação básica da rede pública do estado nos últimos dez anos. Consoante com esse objetivo, a pesquisa buscou analisar, ainda, em 
que medida os docentes reconheceram a atuação dos Centros e se as propostas de formação continuada atenderam a suas necessidades formativas.

A criação dos CEFAPROs deu-se no ano de 1997, por meio do Decreto Estadual n².007/1997. No início da década de 2000, os Centros foram, gradativamente, institucionalizados em quinze polos estratégicos, em atendimento à demanda da oferta de formação continuada de Mato Grosso (MELLO, $2018)$.

\section{Formação continuada de professores}

A formação continuada de professores, compreendida enquanto uma necessidade, sofre consequências decorrentes do processo de globalização que pressiona os estados-nação que, por sua vez, pressionam as instituições formadoras a implementarem políticas de formação continuada que geralmente não atendem às demandas e às necessidades formativas dos professores. Mesmo porque a forte tendência frente a esse contexto é a oferta da formação continuada reafirmar o modelo da racionalidade técnica, limitando-se a repasses de informações de políticas públicas educacionais intermitentes, institucionalizadas nas escolas de forma verticalizada. Com isso, os questionamentos e as reflexões acerca das condições em que acontece o trabalho docente na escola e na sala de aula são prejudicados (MOROSINI, 2009).

Com referência a esse panorama, Imbernón (2010a, p. 19) assegura que na década de 1980 houve o predomínio da racionalidade técnica e do desenvolvimento das competências para se tornar um bom professor. Fase paradoxal que marcou a crise de valores que deu origem a uma nova racionalidade. A formação, pautada na concepção de ciência positivista, na "[...] visão técnica de um ofício no qual havia soluções teóricas para tudo e para todos. Acreditaram nisso ou se forçaram a crer, para depois colocar tudo em quarentena. Alguns ainda não superaram isso" (IMBERNÓN, $2010 a$, p. 19).

A Lei de Diretrizes e Bases da Educação Nacional n. 9.394/96 de 20 de dezembro de 1996 institui em seu artigo 87, parágrafo 4, que "[...] até o fim da Década da Educação somente serão admitidos professores habilitados em nível superior ou formados por treinamento em serviço" (BRASIL, 1996, p. 32). Ou seja, uma referência, aplicada ao nosso contexto, da dimensão do treinamento da formação de professor. Com referência a essa epistemologia 
Aspectos da política de formação continuada de professores implementada pelos CEFAPROs de Mato Grosso

de formação, Fidalgo, Oliveira e Fidalgo (2009) asseveram que os professores, ao mesmo tempo em que assumem o papel de técnicos, são reduzidos a executores das reformas verticalmente impostas, porque não são cooptados a se engajar politicamente com as causas diretamente ligadas ao trabalho docente que exercem na escola. Assim, constituem-se apenas em agentes implementadores das emergentes reformas instituídas pelos organismos internacionais. Todavia, diante dessa conjuntura, ressalta-se que:

A 'formação continuada' hoje precisa ser entendida como um mecanismo de permanente capacitação reflexiva de todos os seres humanos às múltiplas exigências/desafios que a ciência, a tecnologia e o mundo do (não) trabalho colocam (ESTRELA, 2006, p. 19 e 20).

A autora argumenta, ainda, que o processo de globalização impôs, em intensa proporção, normas e exigências a todo planeta. A formação continuada de professores constitui-se em um dos exemplos da necessidade de se educar, e reeducar continuamente, mediante a exigência de se intensificar as reformas na educação formal em atenção às demandas dos sistemas 4 produtivos.

Neste contexto, um dos sinais desses ditames do mundo globalizado, segundo Silva (2014), são as demandas de formação continuada em atendimento às exigências dos organismos internacionais como a Organização para a Cooperação e Desenvolvimento Econômico (OCDE) e a Organização das Nações Unidas para a Educação, a Ciência e a Cultura (UNESCO). Essas ideias são reafirmadas por Estrela (2006, p. 43) ao contextualizar que as políticas educativas têm expressivamente privilegiado as exigências dos "[...] organismos internacionais, como a OCDE e a UNESCO em que a preocupação pela formação contínua de professores tem marcado o discurso e a agenda das políticas educativas dos últimos decênios, pelo menos nos países ditos desenvolvidos". Com isso, segundo a autora, as agências multilaterais imprimiram às políticas públicas de formação continuada de professores a exacerbada preocupação nas condições de eficiência e eficácia das inovações requeridas pelas transformações emergentes da atual sociedade. Com isso, a oferta da formação continuada pautada na realidade de cada escola, na reflexão e na autonomia do professor não se concretiza. 
Estrela (2006, p. 44) argumenta que em "[...] face do negócio que a formação pode ter, com as suas agências e os seus agentes, os seus materiais 'prontos a aplicar', as suas consultorias e avaliações externas, os seus interesses políticos e econômicos [...]", a dimensão nobre da formação continuada é desconsiderada, uma vez que a real necessidade dos professores, dos estudantes, da escola e da comunidade é suprimida em detrimento dos interesses políticos e hegemônicos.

Dada essa realidade, Imbernón (2010a) tece rigorosa crítica aos modelos de formação centrados nos pressupostos da racionalidade técnico-formadora fortemente privilegiada nos últimos trinta anos do século XX. Nesse período, segundo o mesmo autor, foram produzidas expressivas teorizações e discursos em torno do processo de formação continuada de professores. Porém poucas mudanças aconteceram, visto que as inúmeras proposições atinentes às práticas formadoras ficaram tão somente nos planos redigidos em documentos impressos.

Com referência às práticas formativas, Nóvoa (201 1, p. 19) elucida que muitos programas de formação continuada têm se caracterizado como ações inúteis, que complexificam ainda mais o cotidiano docente que, por sua vez, já é extremamente exigente. Por esta razão, o autor defende a necessidade da formação continuada ser compreendida pelos docentes como uma aprendizagem que se estende ao longo da vida que "[...] justifica-se como direito da pessoa e como necessidade da profissão, mas não como obrigação ou constrangimento [...]". Assim, afirma a necessidade dos professores questionarem as propostas de formação que tenham características de "mercado da formação", por isso, fomenta e se justifica por discursos e sentimentos de "desatualização" dos professores. Para o autor, uma das alternativas viável é o investimento em projetos de formação continuada, potencializados pelos princípios de rede de trabalho coletivo e colaborativo, com compartilhamento de ideias e diálogo profissional.

Para ruptura dos modelos de formação referenciados nos pressupostos do paradigma da racionalidade técnica, Imbernón (2010, p. 19) defende a necessidade do professor "[...] desenvolver capacidades de aprendizagem da relação, da convivência, da cultura do contexto e da interação de cada pessoa com o resto do grupo, com seus semelhantes e com a comunidade que envolve a educação". 
Aspectos da política de formação continuada de professores implementada pelos CEFAPROs de Mato Grosso

Assim, a assunção da formação continuada como evento potencializador de novas capacidades de aprendizagem inerentes às demandas da atuação docente implica na criação de práticas formativas em atenção à realidade contextual das vivências cotidianas do professor em sala de aula, como, também, dos atuais desafios do exercício profissional. Sob essa perspectiva, a formação continuada constitui-se um evento que pauta suas ações na reflexão crítica e no reconhecimento dos amplos aspectos sociais e suas respectivas interferências no dia a dia do trabalho docente (BRASIL, 2005).

As diretrizes para a formação inicial em nível superior e para a formação continuada no Brasil orientam a formação como um processo dinâmico e contextualizado, por isso, a intencionalidade incide na busca permanente do desenvolvimento da educação e da valorização dos profissionais docentes (BRASIL, 2015). Conforme o referido documento, a formação continuada pressupõe a adoção de uma concepção que valorize o protagonismo do professor nas diferentes frentes de produção dos conhecimentos científicos, com vistas à consolidação de inovações nas práticas de sala de aula. Por isso, os projetos de formação continuada necessitam levar em conta:

I - os sistemas e as redes de ensino, o projeto pedagógico das instituições de Educação Básica, bem como os problemas e os desafios da escola e do contexto onde ela está inserida;

II - a necessidade de acompanhar a inovação e o desenvolvimento associados ao conhecimento, à ciência e à tecnologia;

III - o respeito ao protagonismo do professor e a um espaço-tempo que the permita refletir criticamente e aperfeiçoar sua prática;

IV - o diálogo e a parceria com atores e instituições competentes, capazes de contribuir para alavancar novos patamares de qualidade ao complexo trabalho de gestão da sala de aula e da instituição educativa (BRASIL, 2015, p. 14).

Com referência à formação continuada, o mesmo documento destaca, ainda, que:

[...] compreende dimensões coletivas, organizacionais e profissionais, bem como o repensar do processo pedagógico, dos saberes e valores, e envolvem atividades de extensão, grupos de estudos, reuniões pedagógicas, cursos, programas e ações para além da formação mínima exigida ao exercício do magistério na Educação 
Básica, tendo como principal finalidade a reflexão sobre a prática educacional e a busca de aperfeiçoamento técnico, pedagógico, ético e políitico do profissional docente (BRASIL, 2015, p. 13).

Consoante essas dimensões, Imbernón (2010a, p. 9) recomenda que as ações de formação continuada aconteçam no próprio local de trabalho dos professores, uma vez que "tudo o que explica não serve para todos nem se aplica a todos os lugares. $\bigcirc$ contexto condicionará as práticas formadoras, bem como sua repercussão nos professores, e, sem dúvida, na inovação e na mudança". As práticas formadoras são definidas como "a atividade de produção e reprodução de formas de entender a formação, na qual o professor estabelece relações mútuas e formas de interpretar a educação" (IMBERNÓN, $2010 a$, p. 12).

Sob essa perspectiva, as propostas de formação continuada de professores seriam instituídas para consolidar a ruptura da cultura, do individualismo e do isolamento dos professores instalados no espaço escolar, uma vez que a formação pensada na dimensão coletiva valoriza o diálogo, o debate, a indagação, a ajuda mútua e solidária e a reflexão como pilares fundantes das práticas colaborativas. Essa proposta de prática formadora, caracteriza-se por uma metodologia que, necessariamente, tem a preocupação em:

[...] propiciar uma aprendizagem da colegialidade participativa; estabelecer uma sequência formadora que parta dos interesses e das necessidades dos assistentes da formação; partir da prática dos professores; criar um clima de escuta ativa e de comunicação; elaborar projetos de trabalho em conjunto; superar as resistências ao trabalho colaborativo e conhecer as diversas culturas da instituição (IMBERNÒN, 201 a, p. 65).

Esses princípios pautam-se no reconhecimento de uma metodologia que concebe a formação continuada como espaço potencializador de ações que favoreçam a constituição de novos conhecimentos centrados na localidade, na diversidade, na heterogeneidade dos professores e estudantes. Esses conhecimentos são continuamente recriados e reinventados, no sentido de contestar e questionar a homogeneização e os modelos de formação e, por conseguinte, as exigências de reformas do ensino decorrentes do processo de globalização (SILVA, 2014). 


\section{Abordagem metodológica: a formação continuada no âmbito dos CEFAPROs}

Em consonância aos objetivos descritos, o estudo fundamentou-se nos princípios do método de pesquisa qualitativa. Para Bogdan e Biklen (2013), apesar da subjetividade desse tipo de pesquisa, esse método possibilita a compreensão dos aspectos descritivos relativos aos fenômenos analisados em um contexto específico. Neste caso, as diferentes situações, vivências e experiências dos inquiridos registradas nos questionários, sob a forma relatos, foram valorizadas pelos pesquisadores no decorrer da categorização e análise dos dados.

Os pesquisadores são docentes que atuavam na formação inicial e continuada de professores. Essa condição viabilizou a elaboração de um roteiro com questões vinculadas aos objetivos propostos, que agregou questionamentos objetivos e subjetivos em consonância à intencionalidade da pesquisa. Dada a extensão geográfica que a pesquisa abarcou, o encaminhamento do questionário e a sua devolução, deu-se via e-mail. Os CEFAPROs, situados nos municípios de Juara/MT, Sinop/MT e Cáceres/MT, encaminharam o material aos docentes que atuavam nos municípios de abrangência da pesquisa.

Em observação aos aspectos éticos, os inquiridos assinaram o Termo de Consentimento Livre e Esclarecido (TCLE). A coleta de informações ocorreu nas escolas, localizadas em 36 municípios jurisdicionados aos polos dos referidos CEFAPROs. Nestes termos, a pesquisa resultou de parcerias firmadas com os Centros dos polos situados nos municípios de Juara/MT, Sinop/Mte Cáceres/MT e com a Universidade do Estado de Mato Grosso (UNEMAT), campi localizados nesses mesmos municípios-polo.

Para o tratamento e análise das informações, utilizaram-se o método de Análise de Conteúdo (BARDIN, 2009). Este método consiste em um conjunto de técnicas que são utilizadas para analisar conteúdos de qualquer natureza, seja documental ou de informações empíricas, que, posteriormente sistematizadas, poderão gerar inferências. Neste sentido, diferentes técnicas delinearam as análises das informações que formaram o corpus documental da pesquisa: a decodificação em unidade de análise, a categorização e a produção de metatexto ou síntese. 
As análises se basearam nos estudos e produções de pesquisadores da atual conjuntura socioeconômica e política a nível mundial, como Castel (1999), Harvey (1992), lanni (1992), Laval (2004). Estes estudiosos contextualizam as implicações dessa conjuntura, que, sob a influência das instâncias internacionais e supranacionais, tendem a definir os rumos das políticas públicas educacionais em todos os seus níveis e modalidades. As análises também se basearam em pesquisadores de políticas públicas educacionais como Frigotto (2010), Lima (2007), Fidalgo, Oliveira e Fidalgo (2009), para os quais, as políticas públicas educacionais implantadas e implementadas sofrem as influências dessas instâncias, por isso, são pontuais, prescritivas, ideológicas, imediatistas e intermitentes.

Pesquisadores da formação inicial e continuada de educadores, como Goodson (2007; 2008), Imbernón (2010; 2010a), Nóvoa (1992; 2011 1), Garcia (1999) e demais estudiosos que abordam os caminhos e os descaminhos da construção do conhecimento docente, na atual conjuntura sociopolítica e econômica, foram consultados para fundamentar as análises dos dados sistematizados neste artigo.

Especificamente, este artigo aditou informações sistematizadas na categoria que vinculou as ações de formação continuada ofertada, nos últimos dez anos, pelos CEFAPROs. Assim, analisou-se a sua importância, como também, o atendimento às demandas e necessidades formativas dos docentes. Para tanto, além de identificar o perfil dos professores, colaboradores da pesquisa, se questionou de quais ações de formação continuada participaram e quais dessas propiciaram maior e menor contribuição à atuação docente.

\section{O perfil dos professores colaboradores da pesquisa}

Antes de apresentar o perfil dos professores que contribuíram com a pesquisa, julgou-se relevante contextualizar, brevemente, o atual contexto, considerado por Harvey (1992) de "acumulação flexível", contraditório e tenso para o autor. Ao se referir à profissionalização, o autor afirma que a escolarização e a qualificação profissional não asseguram a inserção e a permanência dos formados ao mundo do trabalho.

Neste contexto, Castel (1999) afirma que as ações são imediatas e o individualismo, a incerteza e a instabilidade são as principais características 
do atual estágio do sistema capitalista. Nesse estágio, a atualização profissional é um dos imperativos, seja sob o enfoque de formação continuada, formação em serviço, formação para o trabalho, qualificação ou capacitação.

Segundo lanni (1997), no sistema econômico, reconhecido como neoliberal, as organizações internacionais e mundiais adotam orientações práticas reservadas ao favorecimento de mercados emergentes. O neoliberalismo aposta no mercado como o organizador social mais eficiente em oposição ao próprio ser humano, ao mesmo tempo em que contesta a participação do Estado nas políticas sociais, dentre elas a educacional.

Neste sentido, a partir do final do século XX, essa orientação política passou a exigir do setor produtivo um novo perfil de trabalhador. Coube à formação inicial a tarefa de qualificar para a flexibilidade profissional e até mesmo para a não atuação na área de formação. Esses imperativos acentuaram-se no início do século XXI e pressionaram os trabalhadores a se preparar para desempenhar funções imediatas e múltiplas do mercado. Neste contexto, o ser humano foi incluído como recurso material, ou seja, como possibilitador de concretização de ações planejadas com objetivos explícitos de aperfeiçoamento, dinamização, produtividade e lucratividade (CASTEL, 1999).

O desenvolvimento científico, associado à globalização econômica, representa a força produtiva que controla os indivíduos e, ao mesmo tempo em que possibilita a emancipação, provoca a alienação e o controle técnico e social de forma exacerbada. Assim, exclui a maior parte da população mundial daquilo que the é de direito, acentua e repagina a instabilidade, a dominação e a insegurança social, porque, dentre outras coisas, interfere nas políticas educacionais que se prestam às determinações e imposições deste sistema (IANNI, 1997).

É com essa compreensão que se analisou o universo da pesquisa que categorizou informações acerca do perfil profissional dos professores vinculados aos três CEFAPROs nos últimos anos. 
Ângela Rita Christofolo de Mello | Albina Pereira de Pinho Silva | Cleuza Regina Balan Tabordo

\section{Quadro 1}

A formação inicial dos professores: CEFAPROs dos polos de Juara, Sinop e Cáceres

\begin{tabular}{|c|c|}
\hline Formação Inicial & Quantidade \\
\hline Pedagogia & 41 \\
\hline Letras & 7 \\
\hline Educação Física & 3 \\
\hline Matemática & 7 \\
\hline Ciências Biológicas & 6 \\
\hline História & 7 \\
\hline Geografia & 2 \\
\hline Total & 73 \\
\hline
\end{tabular}

Fonte: Elaboração das autoras mediante informações categorizadas nos relatos dos questionários em dezembro de 2017.

A dificuldade em mapear as informações para a pesquisa deu-se pela indiferença e mesmo pela recusa dos professores em contribuir. Essa indiferença pode estar relacionada a diferentes fatores. Como afirma Frigotto (2010), em uma análise materialista histórica, um fenômeno social vincula-se à uma materialidade objetiva e subjetiva, complexa, conflitante e, muitas vezes, contraditória, que por meio de um esforço de abstração e teorização poderá ser compreendido. Nesse contexto, tal recusa pode sinalizar, dentre outras coisas, resistência à política de formação continuada, implementada na rede pública estadual de Mato Grosso por meio das ações dos CEFAPROs. Esta resistência poderá ser decorrente da pouca contribuição da política para o desenvolvimento das condições de atuação docente.

Segundo Laval (2004, p. 20), o capitalismo flexível tende a deixar os profissionais da educação desluzidos não apenas frente às políticas públicas verticalizadas, como também em relação a toda forma de apropriação de conhecimento em vias de desintegração, pois "[...] é no coração da subjetividade que se instala a contradição que todos os sintomas associados a essa perda de amanhã exprimem". Ao considerar o conhecimento como fator de reprodução, o autor afirma que, consoante à democratização da cultura 
universal, a cultura clássica foi substituída pela cultura de massa. Todavia, adverte que a cultura de massa "[...] está subordinada a três fins específicos: o fim econômico, o fim político e o fim científico" (LAVAL, 2004, p. 21). Com isso, a escolarização muda o seu sentido, e, consequentemente, dos profissionais da educação que são encorajados a adaptar seus perfis aos "[...] caracteres adaptáveis às variações existenciais e profissionais em movimento incessante" (LAVAL 2004, p. 23).

Neste cenário, a análise dos dados concernentes ao perfil dos entrevistados indicou que, dos setenta e três professores colaboradores com a pesquisa, sete possuíam duas licenciaturas. A oferta da segunda licenciatura é mais uma política pública educacional do Ministério da Educação que no Brasil, atende aos imperativos da Educação Ampliada e da Cultura Útil, característica do neoliberalismo que transforma os seres humanos em capital humano para atender às necessárias, adaptações e conformações sociais.

\section{Quadro 2}

\section{Professores com duas licenciaturas: CEFAPROs dos po- los de Juara, Sinop e Cáceres}

\begin{tabular}{|c|c|}
\hline Licenciatura & Quantidade \\
\hline Letras e Inglês & 1 \\
\hline Letras e Pedagogia & 1 \\
\hline História e Pedagogia & 2 \\
\hline Biologia e Matemática & 1 \\
\hline Matemática e Pedagogia & 2 \\
\hline
\end{tabular}

Fonte: Elaboração das autoras mediante informações categorizadas dos questionários respondidos em dezembro de 2017.

Goodson (2008), enfaticamente, afirma que durante muito tempo houve a produção de inúmeros discursos acerca da inércia dos professores frente às mudanças. Posto isso, Silva (2014, p. 20), destaca que "[...] os consensuados discursos sempre foram em função das reformas impostas de cima para baixo aos sistemas escolares, sem, contudo, considerar a história de vida, as experiências, as missões, a carreira e os próprios interesses dos profissionais docentes". Frequentemente, nessas reformas do ensino, segundo Goodson 
(2008, p. 128), "[...] 'jogaram fora o bebê junto com a água do banho' [...]", e, com isso, o sentido da formação continuada.

A reflexão sobre a formação continuada frente aos atuais desafios e dilemas que perpassam a profissão docente mobiliza a pensar a questão da aprendizagem que, na atualidade, caracteriza-se um direito inalienável, tanto para professores, quanto para estudantes da educação básica. Todavia, faz-se necessária a compreensão de que a aprendizagem, conforme preconiza Goodson (2007), pressupõe a motivação pessoal e profissional de cada um, isto é, advém das missões e dos sentidos que cada um atribui à aprendizagem ao longo da vida. Estas condições não são viabilizadas em ofertas de formações verticalizadas.

Goodson (2007) compreende que a aprendizagem vincula-se aos interesses, necessidades e propósitos que cada um assume durante a vida, uma vez que o engajamento pessoal e profissional só acontece quando nos sentimos motivados e interessados pela busca de determinada aprendizagem. Essa não acontece quando o ato formal de aprender é amplamente prescrito nos programas e projetos de formação continuada, mas pressupõe um conjunto de fatores como: envolvimento, engajamento, missões, paixões e propósitos que as pessoas assumem em diferentes momentos de suas vidas.

Os professores, colaboradores desta pesquisa, concluíram suas formações iniciais em diferentes instituições, mas a maioria se formou na Universidade do Estado de Mato Grosso (UNEMAT), nas últimas duas décadas, conforme demonstra o Quadro 3. 


\section{Quadro 3}

Instituições formadoras e ano de conclusão por cursos: CEFAPROs dos polos de Juara, Sinop e Cáceres

\begin{tabular}{|c|c|c|}
\hline \multicolumn{3}{|c|}{ Pedagogia } \\
\hline Instituições formadoras & Quantidade & Ano de conclusão \\
\hline UNEMAT & 20 & 2000 a 2015 \\
\hline FAPAN & 1 & 2014 \\
\hline FAEL & 2 & 2013 e 2015 \\
\hline UNITINS & 2 & 2007 e 2012 \\
\hline UNINTER & 7 & 2012,2015, \\
\hline FACINTER & 2016 \\
\hline ULBRA & 3 & 2010,2011 \\
\hline UESPI & 1 & 2011 \\
\hline UFMT & 2 & 1990 \\
\hline UNIGRAN & 1 & 2008,2012 \\
\hline UNIVAG & 1 & 2009 \\
\hline
\end{tabular}

\begin{tabular}{|c|c|c|}
\hline \multicolumn{3}{|c|}{ Ciências Biológicas } \\
\hline Instituições formadoras & Quantidade & Ano de conclusão \\
\hline UNIC & 1 & 2010 \\
\hline UNEMAT & 14 & $\begin{array}{c}1995,2004 \\
2009,2015\end{array}$ \\
\hline
\end{tabular}

\begin{tabular}{|c|c|c|}
\hline \multicolumn{3}{|c|}{ Educação Física } \\
\hline Instituições formadoras & Quantidade & Ano de conclusão \\
\hline FCARP & 2 & 2009 \\
\hline FIFASUL & 3 & 2005 \\
\hline FASIP & 1 & 2013 \\
\hline
\end{tabular}


Ângela Rita Christofolo de Mello | Albina Pereira de Pinho Silva | Cleuza Regina Balan Tabordo

Quadro 3 (continuação)

Instituições formadoras e ano de conclusão por cursos: CEFAPROs dos polos de Juara, Sinop e Cáceres

\begin{tabular}{|c|c|c|}
\hline \multicolumn{3}{|c|}{ Licenciatura em Letras } \\
\hline Instituições formadoras & Quantidade & Ano de conclusão \\
\hline UNINOVA & 1 & 2008 \\
\hline UNEMAT & 23 & $\begin{array}{c}1995, \quad 1998, \\
2003, \quad 2007, \\
2010\end{array}$ \\
\hline UNIOESTE & 5 & 1997 \\
\hline
\end{tabular}

\begin{tabular}{|c|c|c|}
\hline \multicolumn{3}{|c|}{ Licenciatura em História } \\
\hline Instituições formadoras & Quantidade & Ano de conclusão \\
\hline \multirow{2}{*}{ UNEMAT } & 21 & 2004,2007, \\
2009,2014, \\
2016,
\end{tabular}

\begin{tabular}{|c|c|c|}
\hline \multicolumn{3}{|c|}{ Licenciatura em Geografia } \\
\hline Instituições formadoras & Quantidade & Ano de conclusão \\
\hline UNEMAT & 1 & 2005 \\
\hline UNIVAG & 2 & 2008 \\
\hline
\end{tabular}

\begin{tabular}{|c|c|c|}
\hline \multicolumn{3}{|c|}{ Licenciatura em Matemática } \\
\hline Instituições formadoras & Quantidade & Ano de conclusão \\
\hline UNEMAT & 19 & $\begin{array}{cc}1990, & 1995, \\
2000, & 2006, \\
2009\end{array}$ \\
\hline UNIVAG & 11 & 2003,2004 \\
\hline
\end{tabular}

Fonte: Elaboração das autoras mediante informações categorizadas dos questionários respondidos em dezembro de 2017.

Sob a ótica da Teoria do Capital Humano, Mészáros (2005) argumenta que as políticas públicas educacionais são implantadas em atendimento às necessidades produtivas para manter o crescimento econômico. Com o objetivo de adaptar a oferta educacional ao sistema econômico, conforme 
Aspectos da política de formação continuada de professores implementada pelos CEFAPROs de Mato Grosso

o autor, a educação tem a função de produzir conformidades e mascarar o quadro social. Sob esta influência, assenta sua oferta nos princípios da competitividade, da produtividade e da flexibilidade e se volta para a racionalidade mercantil.

Como afirma Lima (2012), não é fácil gerir aspectos democráticos em uma ordem capitalista quase que mundial. Apesar disso, a UNEMAT é uma instituição de educação superior, nacionalmente reconhecida pelo seu aspecto democrático e integrador. A sua principal referência é ofertar formação em nível de licenciaturas e bacharelados no interior de Mato Grosso. Nas últimas décadas, ofertou, também, vários cursos de pós-graduações lato sensu e, nos últimos dez anos, gradativamente, vêm institucionalizando cursos de pós-graduações stricto sensu em nível de mestrado e doutorado em diversas áreas do conhecimento. Todavia, essa oferta é muito tímida, por isso, não atende à demanda potencial do estado.

Neste contexto, a ampliação da oferta de cursos stricto sensu condiciona-se, dentre outros aspectos, à superação da ideologia "[...] de educação como ajustamento às 'necessidades objetivas' da economia e da aprendizagem como amestração" (LIMA, 2012, p. 64). Para o referido autor, a educação precisa ser resgatada e compreendida como "[...] espaço potencialmente divergente, em relativa desconexão face às exigências imediatistas e unilaterais da economia". Com esta compreensão, pode-se afirmar que a educação supera a preparação para a vida e a mera adaptação ao mundo do trabalho.

Os professores que responderam aos questionamentos tinham de um a vinte e oito anos de experiências em docência na educação básica. Aproximadamente $70 \%$, entre 1 a 10 anos de atuação docente, e 30\%, entre 10 a 28 anos. Esses professores atuavam em diferentes áreas do conhecimento da educação básica, mas a maioria, licenciada em pedagogia, atuava nos anos iniciais. Dentre os setenta e três professores, dois não possuíam pós-graduação lato sensu, os demais eram pós-graduados, vários com mais de uma especialização. Do total de setenta e três, apenas quatro possuíam pós-graduação stricto sensu, em nível de mestrado. Dois com mestrado em Educação e dois com mestrado em Ciências Ambientais. 


\section{Envolvimento dos professores com a formação continuada}

Em atenção às recomendações do Edital Induzido que financiou essa pesquisa, uma das questões direcionada aos professores indagava de quais ações formativas vinculadas aos CEFAPROs participaram nos últimos dez anos. Todos afirmaram que participaram da formação continuada realizada por meio do Projeto Sala de Educador (PSE). Esse projeto teve, gradativamente, sua implantação nas escolas públicas da rede estadual de Mato Grosso a partir de 2004, passou por várias reformulações no decorrer dos últimos dez anos e o seu foco consistia em atender à demanda formativa de cada escola. Desse modo, a formação ofertada in loco perpassava pela elaboração de um projeto pela escola após levantamento das necessidades formativas apontadas pelos professores. Posteriormente, esse projeto era aprovado pelos CEFAPROs que também tinhama responsabilidade de acompanhar e assessorar os encontros de formação continuada nas escolas (MELLO, 2018). Por meio do PSE, a formação continuada deveria configurar-se em "um processo de autoformação e aprendizagem, [... ] não mais como cursos pontuais e ações individuais desarticuladas da proposta da escola e da necessidade da comunidade escolar" (MATO GROSSO, 2003, p. 10).

Neste sentido, a proposta de formação continuada ofertada, nos últimos anos em Mato Grosso, respaldou-se nas preconizações de Imbernón (2010, p. 35), dentre outros estudiosos, para quem "[...] o fortalecimento da identidade profissional e pessoal dos profissionais está embasada no desenvolvimento de capacidades com o fim de passarem do ensinar ao aprender". Esse princípio vincula-se à oferta de formação continuada que tem como locus de formação a escola e, como referência, o mapeamento das necessidades formativas dos docentes, condição que poderia favorecer, dentre outras coisas, a assunção de posturas crítico-reflexivas destes e, por conseguinte, a constituição da identidade docente, amplamente afetada pelas rápidas transformações políticas, sociais, econômicas e culturais geradas pelos efeitos do processo de globalização.

Todavia, em Mato Grosso, os CEFAPROs foram responsáveis pela implementação de muitas políticas públicas formuladas em âmbito nacional. Foram políticas com estratégias de formação, reconhecidas por Nóvoa (1992) como híbridas e, por Lima (2007), como intermitentes. Dentre essas políticas estão: Gestão da Aprendizagem (2001/2005); Eterno Aprendiz (2006), 
Prolnfantil (2009), PróLetramento (2009), Prolnfo Integrado (2007), Circuito Campeão (2009), Instrumentos da Alfabetização do Centro de Alfabetização Leitura e Escrita (2008), Pacto Nacional pela Alfabetização na Idade Certa (2013), dentre outras.

A participação nesses programas e projetos implementados em Mato Grosso nas últimas décadas foi citada pelos professores ao afirmarem que, além de participar da formação continuada in loco, também participaram dessas propostas de formação pontuais. Esse contexto contrapôs-se às prerrogativas contidas no documento elaborado pela Superintendência de Formação Continuada, ao justificar que o objetivo da oferta de formação continuada pela via dos CEFAPROs promoveria a superação dos modelos de formação com viés de capacitações pontuais e imediatas, desvinculadas da realidade e das necessidades formativas dos professores, que pouco contribuiria para inovações pedagógicas no interior das salas de aulas (MATO GROSSO, 2003).

\section{Contribuição da formação continuada ofertada aos professores}

Neste subitem, categorizaram-se e analisaram-se as respostas dos professores correspondentes às ações realizadas pelos CEFAPROs que mais contribuíram, bem como as que menos colaboraram com a inovação pedagógica. Em linhas gerais, os professores reconheceram a importância e a necessidade da formação continuada como uma possibilidade de atualização docente. A maioria dos professores afirmou que a formação continuada ofertada in loco, por meio do PSE foi a que mais contribuiu, porque atendeu, de forma mais direta, às suas necessidades formativas, como afirmou um professor:

Penso que seja o Projeto Sala de Educador, pois é uma ação que atende às necessidades formativas dos professores, buscando aproximar das reais necessidades vivenciadas em sala de aula. Embora saibam que, por mais que se façam estudos na formação continuada, é difícil atender a todas as dificuldades dos professores (PROF. CEFAPRO, 2017).

O relato aponta que, devido à complexidade da profissão docente, faz-se necessário que os projetos e ações de formação continuada de professores sejam formulados como uma prática formadora contextualizada às 
necessidades e realidades dos docentes. Sobretudo, como uma proposta que reconheça o repertório de conhecimentos e as múltiplas experiências constituídas ao longo da carreira profissional, os aspectos potenciais da prática, mas também os dilemas e fragilidades que permeiam o ofício destes docentes na escola (NÓVOA, 201 1; IMBERNÓN, 2010 e 2010 ; SILVA, 2014).

Outra argumentação, que inúmeras vezes emergiu nas contribuições dos professores, referiu-se às formações continuadas ofertadas no formato de oficinas pedagógicas. Um indicador que se destacou foi uma oficina ofertada pelos CEFAPROS sobre um trabalho de orientação de elaboração de planejamentos. Como demonstraram os dados da pesquisa, "a maior contribuição foi a oficina sobre planos de aula, pois elaboramos um plano de aula pensando nos descritores e habilidades, ou seja, no que vamos trabalhar na sala de aula" (PROF. CEFAPRO 2017). "A elaboração dos planejamentos contribuiu muito para o desenvolvimento da prática pedagógica" (PROF. CEFAPRO, 2017).

Esses excertos dos professores reafirmam o conceito de "formação" de adultos, proposto por Vaillant e Garcia (2001), quando reconhecem que o processo se viabiliza mediante a interformação entre sujeitos, em que os professores formadores têm a possibilidade de criar contextos e situações de aprendizagem que favoreçam a busca dos objetivos de aprendizagem pessoal e profissional. Diante disso, Garcia (1999, p. 47) afirma que "[...] qualquer mudança no ensino, no currículo, depende em grande parte dos professores". Assim, em todo percurso de mudança há sempre a dimensão pessoal que deve ser considerada, visto que "[...] devem afetar a teoria implícita ou subjetiva dos professores".

Com referência à concepção de formação continuada em serviço, Nóvoa (201 1 , p. 1 1) evidencia que essa acontece "[...] numa perspectiva de aprendizagem ao longo da vida [...]", por isso, a formação continuada assegura a aprendizagem docente como também o desenvolvimento profissional dos educadores em processo de formação.

Sob essa perspectiva, Imbernón (2010a, p. 9) assegura que é imprescindivel que a formação continuada não aconteça separada do local de trabalho dos professores. Assim, "o contexto condicionará as práticas formadoras, bem como sua repercussão nos professores, e, sem dúvida, na inovação e na mudança". Não por acaso, as contribuições dos professores destacaram 
a oferta de formação continuada in loco como a mais significativa para a atuação docente.

\section{Apontamentos: os CEFAPROs enquanto instâncias de formação continuada de Mato Grosso}

Os CEFAPROs, estrategicamente localizados em quinze municípios polos de Mato Grosso, tinham a responsabilidade de promover a política de formação continuada por meio da organização e execução de projetos e programas da SEDUC/MT, bem como do desenvolvimento de parcerias com - Ministério da Educação, secretarias municipais de educação, assessorias pedagógicas e instituições de educação superior (MELLO, 2018).

Em que pesem a efetivação dessa política de formação continuada no que se refere à qualificação e valorização dos profissionais da educação básica, como a principal referência desse órgão. Os Centros atenderam tanto à demanda das escolas, como da SEDUC e se constituíram como polos disseminadores dos programas, projetos e diretrizes educacionais. Contudo, com 20 uma proposta de formação continuada descentralizada e in loco, os conteúdos da formação deveriam ser decididos pelas escolas em atenção às suas particularidades e necessidades formativas (MELLO, 2018).

Dentre as atribuições de responsabilidade dos Centros, destacou-se - Projeto Sala de Professor (PSE), implantado nas escolas estaduais de Mato Grosso, progressivamente, a partir do ano de 2005, com a finalidade de fomentar as ações de formação continuada nas escolas. O PSE fora reformulado, em 2011, e de acordo com o parecer Orientativo n $01 / 2011$, denominado "Sala de Educador" seu objetivo seria "[... fortalecer a escola como locus de formação continuada, por meio da organização de grupos de estudos". Depois disso, várias reformulações aconteceram, tanto que as informações coletadas indicaram que a formação continuada ofertada por meio desse projeto não atendeu as expectativas de aproximadamente 50\% dos docentes, apesar de ser reconhecida e valorizada por boa parte dos professores.

São inúmeras as reclamações apontadas pelos professores que justificaram a insatisfação em relação à política de formação continuada adotada pelo estado, como demostraram as respostas: "O Projeto Sala do Educador da 
minha escola não contribuiu em nada com a minha atuação profissional, porque quem estava desenvolvendo na escola não entendia a proposta" (PROF. CEFAPRO, 2017). "[...] geralmente somos obrigados a seguir um roteiro de estudo imposto pela SEDUC, que muitas vezes foge das necessidades vivenciadas na escola" (PROF. CEFAPRO, 2017).

O Projeto Sala de Educador foi uma ação totalmente inútil, onde a SEDUC/CEFAPRO não respeitou as necessidades formativas das escolas, impondo temas e ações descabidas para a formação continuada. A proposição de temas fora das necessidades das escolas gerou muito descontentamento entre os professores durante as atividades (PROF. CEFAPRO, 2017).

Incluíram-se nas ações de formação continuada, consideradas descontextualizadas pelos professores, as tarefas que deveriam realizar e apresentar na formação seguinte, os relatórios cobrados por algumas escolas após a realização de cada encontro, as leituras determinadas pela SEDUC/MT, o pouco aprofundamento teórico das coordenações de formação continuada, a desarticulação entre teoria e prática, a ausência de planejamento e de foco nos encontros, dentre outros fatores apontados como desfavoráveis à política analisada, como demonstra o excerto a seguir:

A falta de autonomia para o desenvolvimento dos temas, para escolher a metodologia de formação, as exigências de última hora, as reuniões de um dia para o outro, de um modo geral percebe-se a falta de planejamento e muitas cobranças por parte do CEFAPRO (PROF. CEFAPRO, 2017).

Os diferentes e contraditórios dilemas e perspectivas apontados pelos professores são inúmeros. Os relatos retrataram um contexto adverso e conflituoso em que subjugadas às políticas verticalizadas impostas pela SEDUC/MT, as demandas das necessidades formativas dos professores são desconsideradas. Desse modo, a formação continuada ofertada pela via dos CEFAPROs distanciou-se da prática da reflexibilidade que conduz a autonomia docente.

Contudo, a conjuntura analisada, dentre outros aspectos, reedita que a oferta de formação continuada, necessariamente pauta-se nas reflexões das ações realizadas pelos professores no interior das salas de aulas (CONTRERAS, 2002). Neste sentido, propiciar reflexões voltadas às concepções políticas e 
filosóficas da educação em uma perspectiva transformadora na formação continuada poderá contribuir para que o professor encontre no continuum processo formativo, respaldos para realizar uma prática educativa direcionada para uma politização democrática que promova a ruptura da mera adaptação e conformação social.

\section{Referências}

BARDIN, Laurence. Análise de conteúdo. Tradução de Luís A. Reto e Augusto Pinheiro. 5 ed. Lisboa: Edições 70, 2009.

BOGDAN, Robert de; BIKLEN, Sari. Investigação qualitativa em educação: uma introdução à teoria e aos métodos. Edição: Porto Editora, dezembro de 2013

BRASIL. Lei n 9394, de 20 de dezembro de 1996. Estabelece as diretrizes e bases da educação nacional. Diário Oficial [da] República Federativa do Brasil, Brasília, DF v. 134 , n. 248, 23 dez. 1996.

BRASIL. Ministério da Educação e Cultura. Secretaria da Educação Básica. Rede nacional

22 de formação continuada de professores de Educação Básica: orientações gerais. Brasilia/ DF: 2005.

BRASIL, Ministério da Educação. Conselho Nacional de Educação. Resolução $\mathbf{n}^{\circ}$. 2, de $\mathbf{1}^{\circ}$ de julho de 2015. Diretrizes Curriculares Nacionais para a formação inicial em nível superior (cursos de licenciatura, cursos de formação pedagógica para graduados e cursos de segunda licenciatura) e para a formação continuada. Brasília/DF: 2015, 16 p.

CASTEL, Robert. As metamorfoses da questão social: uma crônica do salário. Petrópolis: Vozes, 1999.

CONTRERAS, José. Autonomia de professores. Tradução Sandra Trabucco Valenzuela. São Paulo: Editora Cortez, 2002.

ESTRELA, Maria Tereza. A formação contínua entre a teoria e a prática. In: FERREIRA, Naura Syria. Capareto. (Org.). Formação continuada e gestão da educação. 2. ed. São Paulo: Cortez, 2006.

FAVRETTO, Ivone de Oliveira Guimarães. A formação continuada dos professores em exercício nas escolas públicas de Rondonópolis-MT: uma investigação sobre as instâncias Formadoras. 2006, 141 p. Dissertação (Mestrado em Educação) - Programa de 
Ângela Rita Christofolo de Mello | Albina Pereira de Pinho Silva | Cleuza Regina Balan Tabordo

Pós-Graduação em Educação no Instituto de Educação da Universidade Federal de Mato Grosso, Cuiabá:UFMT/IE, 2006.

FIDALGO, Fernando; OLIVEIRA, Maria Auxiliadora Monteiro; FIDALGO, Nara Luciene Rocha (Org.). Trabalho docente, formação continuada e tecnologias. A intensificação do trabalho docente: tecnologias e produtividade. Campinas: Papirus, 2009.

FRIGOTTO, Galdêncio. A produtividade da escola improdutiva: um (re) exame das relações entre educação e estrutura econômico-social capitalista. 9. ed. São Paulo: Cortez, 2010.

GOODSON, Ivor Freferick. Currículo, narrativa e o futuro social. Revista Brasileira de Educação, Rio de Janeiro, v. 12 n. 35, p. 241-252, maio/ago. 2007. (Tradução Eurize Caldas Pessanha e Marta Banducci Rahe).

GOODSON, Ivor Freferick. As políticas de currículo e de escolarização: abordagens históricas. Tradução Vera Joscelyne. Petrópolis: Vozes, 2008.

HARVEY, David. Condição pós-moderna. São Paulo: Loyola, 1992.

IANNI, Octavio. A sociedade global. 5. ed. Rio de Janeiro: Civilização Brasileira, 1997.

IMBERNÓN, Francisco. Formação docente e profissional: formar-se para a mudança e a incerteza. 7. ed. São Paulo: Cortez, 2010.

IMBERNÓN, Francisco. Formação continuada de professores. Tradução Juliana dos Santos Padilha. Porto Alegre: Artmed, 2010 a.

LAVAL, Christian. A escola não é uma empresa: o neoliberalismo em ataque ao ensino público. Londrina: Editora Planta, 2004.

LIMA, Licínio. Aprender para ganhar, conhecer para competir: sobre a subordinação da educação na "sociedade da aprendizagem". São Paulo: Cortez, 2012.

GARCIA, Carlos Marcelo. Formação de professores: para mudança educativa. Porto, Portugal: Porto Editora, 1999.

MATO GROSSO, Secretaria de Estado de Educação - SEDUC/MT. CEFAPROs e NTEs. 2003. Disponível em: http://www.seduc.mt.gov.br/conteudo. php?sid=79. Acesso em: 8 jun. 2012.

MATO GROSSO. Programa de formação continuada sala de professor. Cuiabá: SUFP/ SEDUC/MT, 2003. 
MATO GROSSO. Política de formação dos profissionais da Educação Básica de Mato Grosso: formação em rede entrelaçando saberes. Cuiabá: SUFP/SEDUC/MT, 2011.

MELLO, Ângela Rita Christofolo de. Uma política educacional para jovens e adultos em Mato Grosso: adaptabilidade e conformação social. Cuiabá: Editora UFMT, 2018.

MÉSZÁROS, István. Education beyond capital. A educação para além do Capital. Tradução Tavares e Isa. São Paulo: Boitempo, 2005.

MOROSINI, Marilia Costa. Qualidade na educação superior: tendências do século. Revista Estudos em Avaliação Educacional, São Paulo, v. 20, n. 43, p. 165-186, maio/ago. 2009 .

NÓVOA, António. O regresso dos professores. Pinhais: Editora Melo, 2011.

NÓVOA, António. Formação de professores e profissão docente. Lisboa: Dom Quixote, 1992.

PROF. CEFAPRO. Relato. Juara (Mato Grosso), 20 dez. 2017.

PROF. CEFAPRO. Relato. Cáceres (Mato Grosso), 20 dez. 2017.

24 PROF. CEFAPRO. Relato. Sinop (Mato Grosso), 20 dez. 2017.

SILVA, Albina Pereira de Pinho. Formação continuada de professores para o projeto UCA análise dos processos formativos prescritos, vivenciados e narrados. 2014. 330 f. Tese (Doutorado em Educação) - Programa de Pós-Graduação em Educação, Universidade Federal do Rio Grande do Sul, Porto Alegre, 2014.

VAlLANT, Denise; GARCIA, Carlos Marcelo. Las tareas del formador. Málaga: Ediciones Alije, 2001.

Profa. Dra. Ângela Rita Christofolo de Mello Universidade do Estado de Mato Grosso (Brasil) Faculdade de Educação e Ciências Sociais Aplicadas Programa de Pós-Graduação em Educação (Campus de Cáceres) Programa de Pós-Graduação Mestrado Profissional em Letras (Campus de Sinop) Líder Grupo de Pesquisa de Formação Docente, Gestão e Prática Educacional (GEFOPE/ 
Profa. Dra. Albina Pereira de Pinho Silva Universidade do Estado de Mato Grosso (Brasil)

Faculdade de Educação e Linguagem

Programa de Pós-Graduação em Letras e

Programa de Pós-Graduação Mestrado Profissional em Letras (Campus de Sinop) Vice-líder do Grupo de Pesquisa de Formação Docente, Gestão e Prática Educacional (GEFOPE/CNPq)

E-mail: albina@unemat.br ORCID: https: / / orcid.org/0000-0002-5 1 39-9299

Profa. Ms. Cleuza Regina Balan Taborda Universidade do Estado de Mato Grosso (Brasil) Faculdade de Educação e Ciências Sociais Aplicadas (Campus de Juara) Grupo de Pesquisa de Formação Docente, Gestão e Prática Educacional (GEFOPE/CNPq) E-mail: cbalan@unemat.br ORCID: https:/ / orcid.org/0000-0001-7375-6093 Recebido 9 abr. 2019 Aceito 26 jul. 2019 